\title{
PERENCANAAN GEOMETRI JALAN \\ BERDASARKAN METODE BINA MARGA MENGGUNAKAN PROGRAM VISUAL BASIC
}

\author{
Eduardi Prahara \\ Jurusan Teknik Sipil, Fakultas Sains dan Teknologi, Universitas Bina Nusantara \\ Jln. K.H. Syahdan No. 9, Palmerah, Jakarta Barat 11480 \\ eduardi@gmail.com
}

\begin{abstract}
One of the main things in a highway construction plan is the geometric design that includes horizontal and vertical alignment design. This study aims to formulate the steps of highway geometric design into Visual Basic 2005 program. The design steps are the calculation of horizontal and vertical alignment. Using Visual Basic 2005, it is expected that the calculation can be done faster than the manual calculation without mistake. The program is validated by comparing results obtained by manual calculations with a difference about 1x10-4 which is considered accurate. As a case study, a geometric road design is conducted in Bogor in 2009 with a fairly low-speed plan 20-40 km/hour. In the plan, the road has 28 PI (Points of Intersection) on the horizontal alignment and 15 PVI (Point of Vertical Intersection) and obtains good results in accordance with requirements and regulations issued by Bina Marga.
\end{abstract}

Keywords: road geometry, Visual Basic 2005, horizontal alignment, vertical alignment.

\begin{abstract}
ABSTRAK
Salah satu hal utama dalam perencanaan konstruksi jalan raya adalah perencanaan geometri yang meliputi perencanaan alinyemen horizontal dan vertikal. Penelitian ini bertujuan memformulasikan tahap perencanaan geometri jalan raya ke dalam program Visual Basic 2005. Tahapan perencanaan ini adalah perhitungan alignment horizontal dan vertikal. Dengan program ini, diharapkan perhitungan yang dilakukan dapat lebih cepat dari perhitungan manual dan tanpa kesalahan. Program ini juga telah divalidasi dengan membandingkan hasil yang diperoleh dengan perhitungan manual dengan selisih sama atau kurang dari $1 \times 10^{-4}$ yang sudah cukup akurat. Sebagai studi kasus, dilakukan perencanaan geometrik jalan kabupaten di Kabupaten Bogor tahun 2009 dengan kecepatan rencana cukup rendah yaitu 20-40 km/jam. Pada perencanaannya, ruas jalan ini memiliki 28 PI (Point of Intersection) pada alignment horizontal dan 15 PVI (Point of Vertical Intersection) dan mendapatkan hasil yang baik sesuai dengan persyaratan dan peraturan perencanaan geometrik yang dikeluarkan oleh Bina Marga.
\end{abstract}

Kata kunci: geometrik jalan, Visual Basic 2005, alinyemen horizontal, alinyemen vertical. 


\section{PENDAHULUAN}

Perencanaan geometrik jalan merupakan hal penting yang harus diperhatikan dalam pelaksanaan konstruksi jalan demi kenyamanan, keamanan, dan kelancaran dalam lalu lintas. Bila perencanaan jalan tidak diperhatikan, maka kelancaran lalu lintas akan terganggu baik dari segi waktu maupun biaya. Oleh karena itu, perencanaan geometrik jalan harus direncanakan sesuai kebutuhan serta kelas jalan berdasarkan jenis moda yang akan dilalui.

Perencanaan geometrik jalan yang baik harus dilakukan dengan pertimbangan yang seoptimal mungkin sesuai dengan kelas jalan dan kecepatan rencananya. Dengan semakin berkembangnya teknologi, khususnya komputer, manusia didorong agar dapat menyelesaikan perhitungan dengan lebih cepat dan akurat. Maka atas pemikiran tersebut perlu dibuat suatu pengembangan program komputer sebagai alat bantu dalam menyelesaikan perhitungan geometrik jalan. Dimana pada dasarnya perhitungan secara manual dengan data yang banyak pula memerlukan waktu yang cukup lama dalam perhitungannya.

Perhitungan geometrik jalan dapat dihitung menggunakan metode konvensional atau secara manual berdasarkan parameter-parameter yang ada. Pada perencanaan geometrik jalan, pemilihan alinyemen horizontal maupun vertikal harus memperhatikan syarat-syarat yang telah ditentukan. Oleh karena itu, proses perhitungan secara manual akan memerlukan ketelitian dan waktu yang cukup lama.Untuk mempercepat dan mempermudah dalam perhitungan, perlu dibuat suatu program yang berfungsi sebagai alat bantu untuk mempermudah dan mempersingkat waktu.

Studi kasus diambil dari perencanaan jalan kabupaten di Kabupaten Bogor tahun 2009. Jalan tersebut direncanakan dengan kecepatan rendah yaitu $20-40 \mathrm{~km} / \mathrm{jam}$. Dari data-data yang didapat, kemiringan medan proyek ini digolongkan ke medan dataran dan perbukitan. Proyek ini direncanakan oleh sebuah konsultan swasta di Jakarta. Gambar 4 merupakan trase proyek ini yang berawal dari titik B menuju titik A. Gambar ini dapat dibandingkan dengan hasil program (lihat Gambar 1).

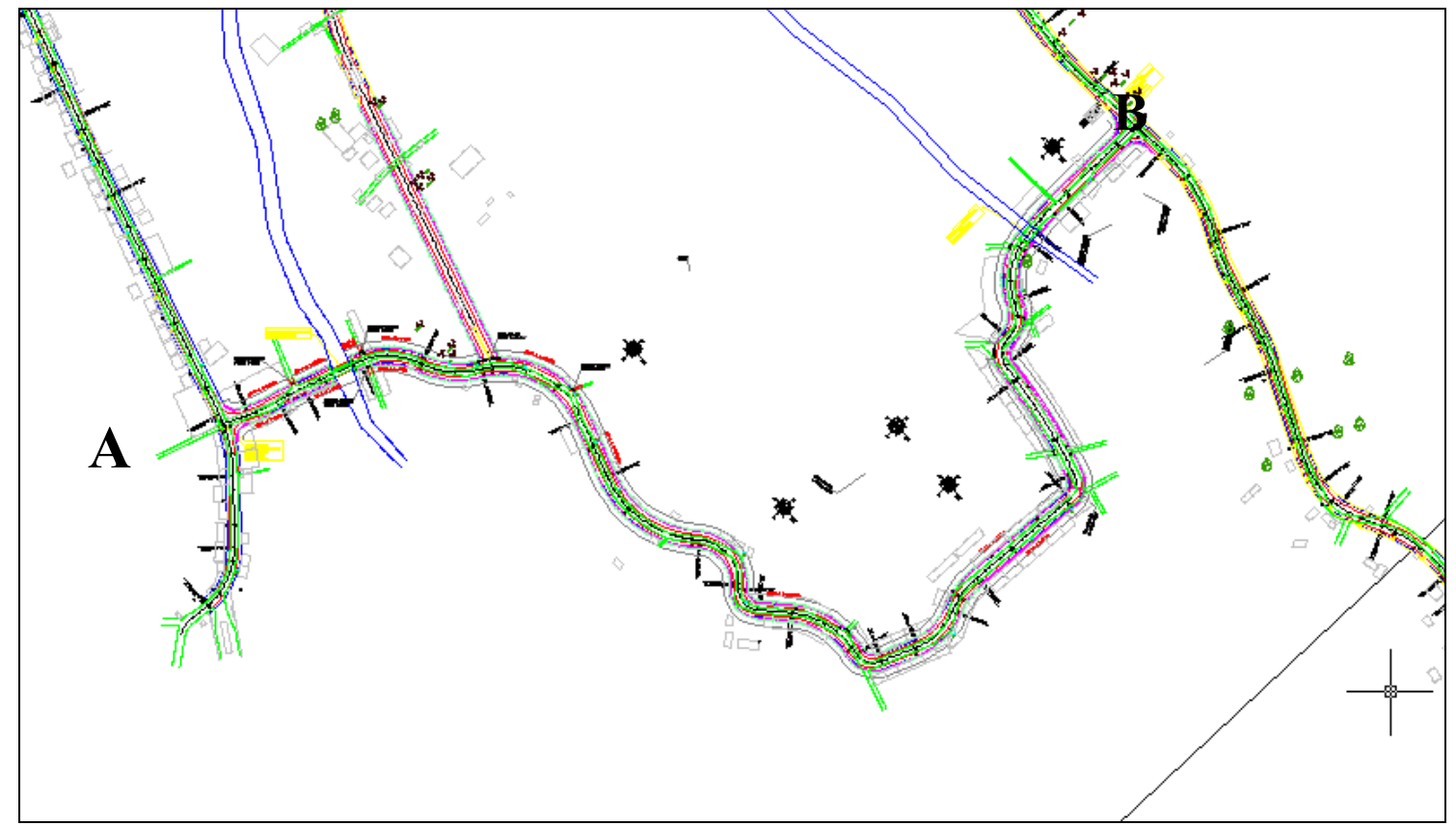

Gambar 1. Trase proyek perencanaan jalan kabupaten. 


\section{METODE}

Perencanaan program perhitungan geometrik jalan ini merupakan perhitungan alinyemen horizontal dan vertical berdasarkan metode Bina Marga menggunakan program Visual Basic 2005. Validasi perhitungan dilakukan dengan membandingkan perhitungan program dan perhitungan manual.

\section{Alinyemen Jalan}

Alinyemen jalan merupakan bagian dari geometrik jalan yang difokuskan pada perencanaan tikungan jalan dan tanjakan maupun turunan suatu jalan. Maka dari itu perencanaan alinyemen jalan harus diperhitungkan dengan baik, agar hasil perencanaan yang didapatkan dapat memberikan kenyamanan dalam berkendara.

\section{Alinyemen Horizontal}

Ditinjau secara keseluruhan, penetapan alinyemen horizontal harus dapat menjamin keselamatan maupun kenyamanan bagi pemakai jalan. Dengan demikian maka menurut peraturan Bina Marga setiap kecepatan rencana yang ditetapkan mempunyai jari-jari minimum yang diperbolehkan untuk direncanakan.

Tabel 1

Panjang Jari-Jari Minimum

\begin{tabular}{|l||l|l|l|l|l|l|l|l|}
\hline $\operatorname{Vr}(\mathbf{k m} / \mathbf{j a m})$ & 120 & 100 & 80 & 60 & 50 & 40 & 30 & 20 \\
\hline $\mathbf{R}_{\min }(\mathbf{m})$ & 600 & 370 & 210 & 110 & 80 & 50 & 30 & 15 \\
\hline
\end{tabular}

Sumber: Tata cara Perencanaan Geometrik Jalan antar kota, Departemen Pekerjaan Umum, 1997.

Adapun jenis kurva dari alinyemen horizontal dibagi menjadi tiga yaitu: (1) Full Circle bentuk tikungan ini dipergunakan apabila dalam perencanaannya diperoleh nilai $\mathrm{R}$ yang besar. Jenis tikungan ini hanya terdiri dari bagian suatu lingkaran saja; (2) Spiral Circle Spiral - bentuk tikungan ini, merupakan lengkung peralihan dari bagian lurus (tangen) menjadi bentuk lingkaran. Fungsi utama dari peralihan lengkung tersebut adalah agar perubahan sentrifugal yang timbul pada waktu kendaraan memasuki atau meninggalkan tikungan dapat terjadi secara berangsur-angsur dan tidak mendadak. Dengan demikian diharapkan agar kendaraan dapat melintasi jalur yang telah disediakan dengan nyaman; (3) Spiral-Spiral - lengkung tanpa busur lingkaran. Pada tikungan spiral-spiral dipergunakan pada tikungan yang tajam. Adapun persamaan yang digunakan untuk mencari parameter tikungan sama seperti parameter yang digunakan pada tikungan spiral circle spiral. Khusus untuk spiral-spiral digunakan bila $\mathrm{L}_{\mathrm{c}}<25$ meter. Menurut Oglesby, Hick RG (1982), khusus untuk tikungan jenis spiralspiral, tikungan ini tidak mempunyai lengkung circle. Maka berlaku kondisi sebagai berikut:

$$
\begin{aligned}
& \theta_{\mathrm{c}}=0, \text { maka } \Delta=2 \theta_{\mathrm{s}} \\
& \mathrm{L}_{\mathrm{c}}=0, \text { maka } \mathrm{L}=2 \mathrm{~L}_{\mathrm{s}}
\end{aligned}
$$

\section{Alinyemen Vertikal}

Alinyemen vertikal dapat dibagi menjadi dua bentuk.Pertama, lengkung vertikal vembung, yaitu lengkung dimana titik perpotongan antara kedua tangen berada di atas permukaan jalan yang bersangkutan. Jenis-jenis lengkung vertikal cembung seperti terlihat pada Gambar 2. 


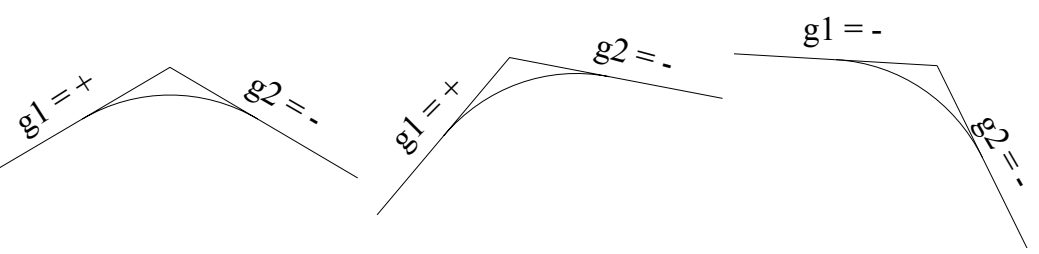

Gambar 2. Jenis lengkung vertikal cembung.

Kedua, lengkung vertikal cekung, yaitu lengkung dimana titik perpotongan antara kedua tangen berada di bawah permukaan jalan. Jenis-jenis lengkung vertikal cembung seperti terlihat pada Gambar 3.

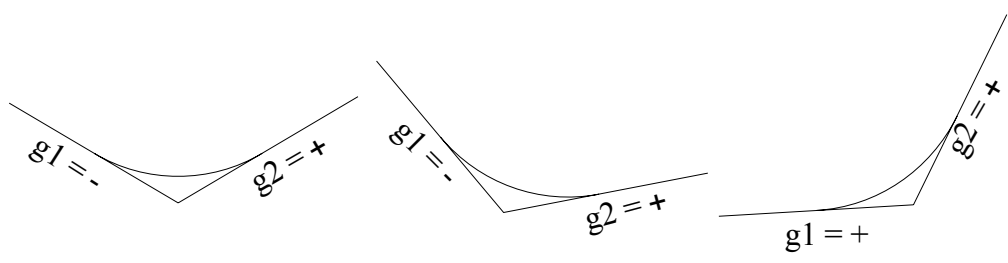

Gambar 3. Jenis lengkung vertikal cekung.

Alur perhitungan perencanaan geometrik jalan secara umum dapat dilihat pada Gambar 4.

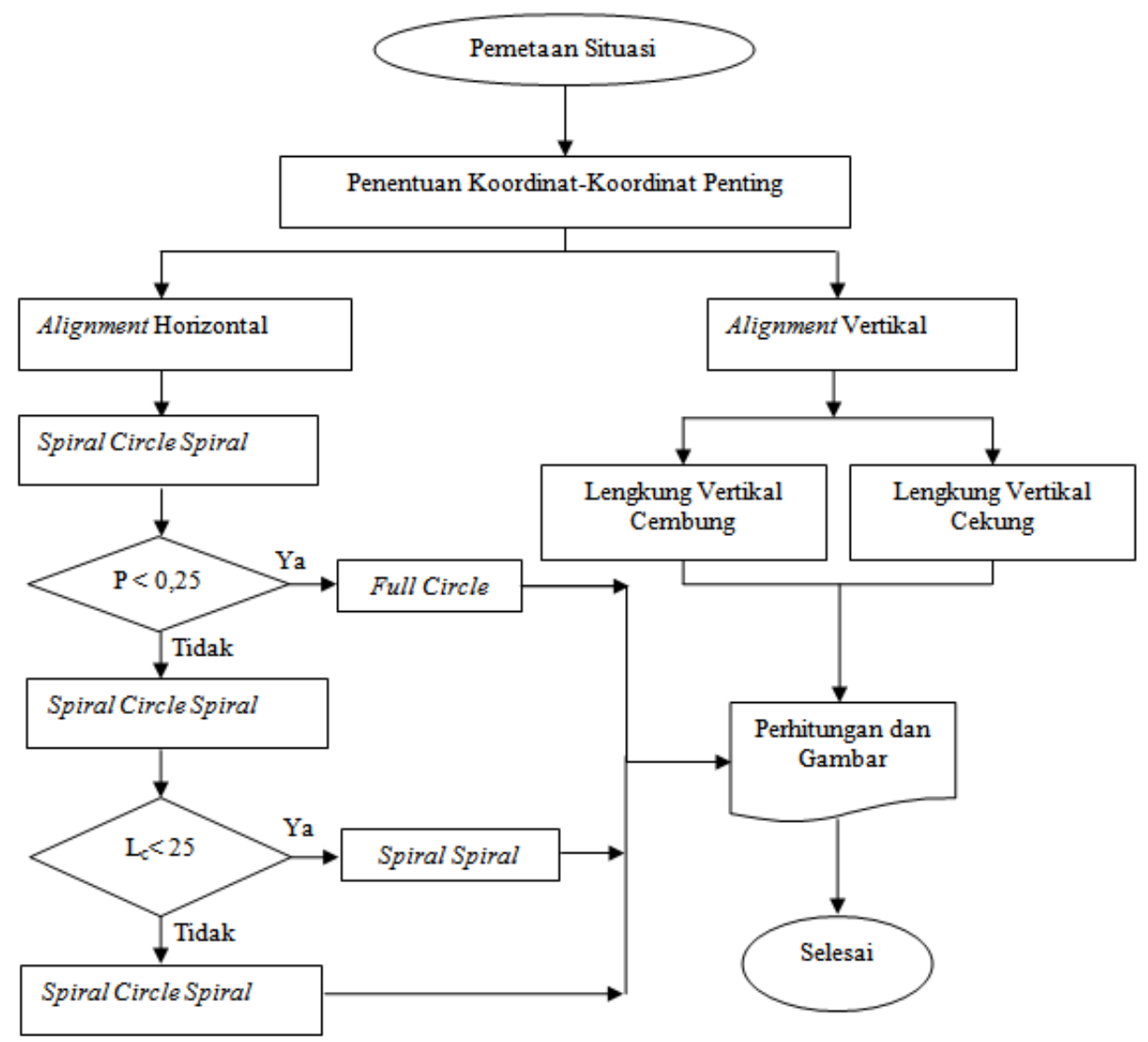

Gambar 4. Bagan alur langkah penentuan tipe alinyemen. 


\section{HASIL DAN PEMBAHASAN}

Validasi program dimaksudkan untuk mengetahui apakah hasil dari perhitungan program ini memenuhi syarat atau tidak, serta layak atau tidaknya program ini untuk dipergunakan. Validasi ini dilakukan dengan membandingkan perhitungan program dan perhitungan manual. Hasil validasi program untuk masing-masing tipe tikungan dan lengkung vertikal dapat dilihat pada Tabel $2-6$.

\section{Perbandingan Hasil Perhitungan Manual dengan Perhitungan Program}

Tabel 2

Perbandingan Hasil Perhitungan Manual dan Program untuk Tikungan Full Circle

\begin{tabular}{crr}
\hline Nilai & \multicolumn{1}{c}{ Manual } & Program \\
\hline $\mathbf{R c}$ & 450 & 450 \\
$\Delta$ & 38.0150 & 38.0154 \\
$\mathbf{L s}$ & 50 & 50 \\
$\mathbf{T}$ & 155.0133 & 155.0133 \\
$\mathbf{E}$ & 25.9508 & 25.9508 \\
$\mathbf{L}$ & 298.5691 & 298.5691 \\
\hline
\end{tabular}

Tabel 3

Perbandingan Hasil Perhitungan Manual dan Program untuk Tikungan Spiral Circle Spiral

\begin{tabular}{|c|c|c|}
\hline Nilai & Manual & Program \\
\hline $\mathbf{R}$ & 150 & 150 \\
\hline$\Delta$ & 38.015 & 38.0154 \\
\hline Ls & 50 & 50 \\
\hline$\Theta \mathbf{s}$ & 9.5493 & 9.5493 \\
\hline Xs & 49.8611 & 49.8611 \\
\hline Ys & 2.7778 & 2.7778 \\
\hline $\mathbf{K}$ & 24.9767 & 24.9767 \\
\hline $\mathbf{P}$ & 0.6993 & 0.6993 \\
\hline $\mathbf{T}$ & 76.8887 & 76.8887 \\
\hline $\mathbf{E}$ & 9.3899 & 9.3898 \\
\hline$\Delta \mathbf{c}$ & 49.523 & 49.523 \\
\hline Ls & 149.532 & 149.532 \\
\hline
\end{tabular}

Tabel 4

Perbandingan Hasil Perhitungan Manual dan Program untuk Tikungan Spiral Spiral

\begin{tabular}{ccc}
\hline Nilai & Manual & Program \\
\hline $\mathbf{R}$ & 115 & 115 \\
$\Delta$ & 38.0150 & 38.0154 \\
@s & 19.0080 & 19.0075 \\
$\mathbf{L s}$ & 76.3030 & 76.3018 \\
$\mathbf{T}$ & 78.3681 & 78.3686 \\
$\mathbf{E}$ & 8.9241 & 8.9242 \\
$\mathbf{L}$ & 152.6060 & 152.6036 \\
\hline
\end{tabular}


Tabel 5

Perbandingan Hasil Perhitungan Manual dan Program untuk Lengkung Vertikal Cekung

\begin{tabular}{lrr}
\hline \multicolumn{1}{c}{ Nilai } & \multicolumn{1}{c}{ Manual } & Program \\
\hline g1 & -6.4935 & -6.4935 \\
g2 & 3.7037 & 3.7037 \\
A & 10.1972 & 10.1972 \\
Ev & 1.9119 & 1.9120 \\
Sta. PVC & $0+079$ & $0+080$ \\
Elev. PVC & 264.8701 & 265.8701 \\
Sta. PVI & $0+154$ & $0+155$ \\
Elev. PVI & 261.912 & 262.912 \\
Sta.PVC & $0+229$ & $0+230$ \\
Elev. PVC & 26.7778 & 27.7778 \\
\hline
\end{tabular}

Tabel 6

Perbandingan Hasil Perhitungan Manual dan Program untuk Lengkung Vertikal Cembung

\begin{tabular}{lrr}
\hline \multicolumn{1}{c}{ Nilai } & Manual & Program \\
\hline g1 & 0.9756 & 0.9756 \\
g2 & -5.8824 & -5.8824 \\
A & -6.858 & -6.858 \\
Ev & 0.8573 & 0.8572 \\
Sta. PVC & $1+500$ & $1+501$ \\
Elev. PVC & 280.5122 & 281.5122 \\
Sta. PVI & $1+550$ & $1+551$ \\
Elev. PVI & 280.1427 & 281.1427 \\
Sta.PVC & $1+600$ & $1+601$ \\
Elev. PVC & 278.0588 & 279.0588 \\
\hline
\end{tabular}

Dari hasil perbandingan tabel diatas, dapat ditarik kesimpulan bahwa program ini cukup valid untuk menghitung tikungan dan lengkungan geometri jalan raya. Selain itu, dilakukan juga studi kasus pada salah satu proyek jalan kabupaten yang telah dilakukan dengan cara manual dan dicoba untuk menghitung dan menggambarkan alinyemen vertikal maupun horizontal dari proyek tersebut.

\section{Hasil Perhitungan Program (Alinyemen Horizontal)}

Tabel $7-10$.

Hasil perhitungan program untuk alinyemen horizontal pada proyek ini dapat di lihat pada

Tabel 7

Hasil Perhitungan Program Titik PI - 1 sampai dengan PI - 7

\begin{tabular}{lrrrrrrr}
\hline \multicolumn{1}{c}{ Tititk } & PI - 1 & \multicolumn{1}{c}{ PI - 2 } & PI - 3 & PI - 4 & PI - 5 & PI - 6 & \multicolumn{1}{c}{ PI - 7 } \\
\hline Tipe & SS & SS & SS & SS & SS & SS & SS \\
$\boldsymbol{\Delta}$ & 26.0041 & 3.2109 & 54.2648 & 31.8445 & 44.0362 & 47.2062 & 10.7314 \\
$\mathbf{V r}$ & 40 & 40 & 30 & 30 & 30 & 30 & 40 \\
$\mathbf{R}$ & 85 & 100 & 43 & 30 & 50 & 30 & 100 \\
$\mathbf{E c} / \mathbf{E s}$ & 2.9949 & 0.0524 & 7.1394 & 1.6061 & 5.3099 & 3.7040 & 0.5873 \\
Tc/Ts & 39.0531 & 5.6050 & 42.6050 & 16.9856 & 39.8520 & 25.7807 & 18.7684 \\
$\boldsymbol{\Theta s}$ & 13.0021 & 1.6054 & 27.1324 & 15.9222 & 22.0181 & 23.6031 & 5.3657 \\
\hline
\end{tabular}




\begin{tabular}{lrrrrrrr}
\hline K & 19.2554 & 2.8019 & 19.9670 & 8.3150 & 19.1164 & 12.2857 & 9.3622 \\
$\mathbf{P}$ & 0.7389 & 0.0131 & 1.6768 & 0.3936 & 1.2759 & 0.8843 & 0.1465 \\
$\mathbf{L s}$ & 38.5779 & 5.6040 & 40.2517 & 16.6737 & 38.4289 & 24.7171 & 18.7299 \\
$\mathbf{L}$ total & 77.1559 & 11.2080 & 80.5035 & 33.3475 & 76.8577 & 49.4342 & 37.4598 \\
$\mathbf{E}$ & 7.9559 & 7.1149 & 8.4692 & 9.8197 & 7.6597 & 9.8197 & 7.1149 \\
\hline
\end{tabular}

Tabel 8

Hasil Perhitungan Program Titik PI - 8 sampai dengan PI - 14

\begin{tabular}{lrrrrrrr}
\hline \multicolumn{1}{c}{ Tititk } & \multicolumn{1}{c}{ PI - 8 } & \multicolumn{1}{c}{ PI - 9 } & \multicolumn{1}{c}{ PI - 10 } & PI - 11 & PI - 12 & PI - 13 & PI - 14 \\
\hline Tipe & SS & SS & SS & SS & SS & SS & SS \\
$\boldsymbol{\Delta}$ & 4.5486 & 25.4869 & 34.1870 & 71.1148 & 73.1130 & 31.0656 & 26.2110 \\
Vr & 40 & 30 & 30 & 20 & 20 & 30 & 20 \\
$\mathbf{R}$ & 100 & 50 & 50 & 30 & 30 & 50 & 30 \\
Ec/Es & 0.1051 & 1.6906 & 3.1040 & 9.4682 & 10.1357 & 2.5427 & 1.0744 \\
Tc/Ts & 7.9418 & 22.5044 & 30.4806 & 41.3075 & 42.7604 & 27.5915 & 13.8958 \\
$\mathbf{~} \mathbf{s}$ & 2.2743 & 12.7435 & 17.0935 & 35.5574 & 36.5565 & 15.5328 & 13.1055 \\
$\mathbf{K}$ & 3.9692 & 11.1022 & 14.8717 & 18.3560 & 18.8550 & 13.5211 & 6.8499 \\
$\mathbf{P}$ & 0.0263 & 0.4173 & 0.7582 & 2.1087 & 2.2398 & 0.6237 & 0.2650 \\
$\mathbf{L s}$ & 7.9388 & 22.2416 & 29.8338 & 37.2356 & 38.2819 & 27.1098 & 13.7240 \\
$\mathbf{L}$ total & 15.8777 & 44.4831 & 59.6676 & 74.4712 & 76.5637 & 54.2196 & 27.4481 \\
$\mathbf{E}$ & 7.1149 & 7.6597 & 7.6597 & 6.1353 & 6.1353 & 7.6597 & 6.1353 \\
\hline
\end{tabular}

Tabel 9

Hasil Perhitungan Program Titik PI - 9 sampai dengan PI - 21

\begin{tabular}{lrrrrrrr}
\hline \multicolumn{1}{c}{ Tititk } & PI - 15 & PI - 16 & PI - 17 & PI - 18 & PI - 19 & PI - 20 & PI - 21 \\
\hline Tipe & SS & SS & SS & SS & SS & SS & SS \\
$\boldsymbol{\Delta}$ & 85.1861 & 51.3850 & 33.5353 & 2.7550 & 77.9153 & 5.4516 & 5.0139 \\
$\mathbf{V r}$ & 20 & 20 & 20 & 40 & 20 & 40 & 40 \\
$\mathbf{R}$ & 15 & 30 & 30 & 200 & 15 & 200 & 200 \\
$\mathbf{E c} / \mathbf{E s}$ & 7.5067 & 4.4628 & 1.7890 & 0.0771 & 5.9454 & 0.3021 & 0.2555 \\
$\mathbf{T c} / \mathbf{T s}$ & 26.1496 & 28.2989 & 17.9248 & 9.6181 & 23.1933 & 19.0396 & 17.5098 \\
$\mathbf{\Theta s}$ & 42.5930 & 25.6925 & 16.7677 & 1.3775 & 38.9577 & 2.7258 & 2.5070 \\
$\mathbf{K}$ & 10.9174 & 13.3579 & 8.7539 & 4.8083 & 10.0240 & 9.5141 & 8.7504 \\
$\mathbf{P}$ & 1.5690 & 1.0556 & 0.4374 & 0.0193 & 1.2873 & 0.0755 & 0.0638 \\
$\mathbf{L s}$ & 22.3017 & 26.9051 & 17.5591 & 9.6168 & 20.3982 & 19.0295 & 17.5020 \\
$\mathbf{L}$ total & 44.6033 & 53.8103 & 35.1181 & 19.2335 & 40.7964 & 38.0591 & 35.0040 \\
$\mathbf{E}$ & 9.3924 & 6.1353 & 6.1353 & 4.0542 & 9.3924 & 4.0542 & 4.0542 \\
\hline
\end{tabular}

Tabel 10

Hasil Perhitungan Program Titik PI - 22 sampai dengan PI - 28

\begin{tabular}{lrrrrrrr}
\hline \multicolumn{1}{c}{ Tititk } & PI - 22 & PI - 23 & PI - 24 & PI - 25 & PI - 26 & PI - 27 & PI - 28 \\
\hline Tipe & SS & SS & SS & SS & SS & SS & SS \\
$\boldsymbol{\Delta}$ & 75.4886 & 52.5056 & 25.6761 & 26.3896 & 6.5051 & 5.2443 & 7.4060 \\
$\mathbf{V r}$ & 20 & 20 & 20 & 30 & 40 & 40 & 40 \\
$\mathbf{R}$ & 15 & 30 & 30 & 30 & 160 & 200 & 200 \\
Ec/Es & 5.4880 & 4.6818 & 1.0299 & 1.0895 & 0.3443 & 0.2795 & 0.5581 \\
\hline
\end{tabular}




\begin{tabular}{lrrrrrrr}
\hline Te/Ts & 22.2647 & 28.9856 & 13.6053 & 13.9930 & 18.1795 & 18.3149 & 25.8770 \\
$\boldsymbol{\theta s}$ & 37.7443 & 26.2528 & 12.8381 & 13.1948 & 3.2526 & 2.6221 & 3.7030 \\
$\mathbf{K}$ & 9.7231 & 13.6447 & 6.7106 & 6.8964 & 9.0819 & 9.1523 & 12.9241 \\
$\mathbf{P}$ & 1.2009 & 1.1044 & 0.2542 & 0.2687 & 0.0860 & 0.0699 & 0.1394 \\
$\mathbf{L s}$ & 19.7629 & 27.4919 & 13.4440 & 13.8176 & 18.1658 & 18.3059 & 25.8518 \\
$\mathbf{L}$ total & 39.5257 & 54.9837 & 26.8880 & 27.6351 & 36.3316 & 36.6118 & 51.7036 \\
$\mathbf{e}$ & 9.3924 & 6.1353 & 6.1353 & 9.8197 & 4.9125 & 4.0542 & 4.0542 \\
\hline
\end{tabular}

\section{Hasil Perhitungan Program (Alinyemen Vertical)} $11-13$

Hasil perhitungan program untuk alinyemen vertikal pada proyek ini dapat di lihat pada Tabel

\section{Hasil Perhitungan Penggambaran Alinyemen Horizontal dan Vertikal}

Untuk memudahkan secara visual, program ini ditambah dengan fasilitas penggambaran alinyemen horizontal dan vertikal, secara otomatis. Hasilnya dapat dilihat pada Gambar 5 dan 6.

Tabel 11

Hasil Perhitungan Program Titik PVI - 1 sampai dengan PVI - 6

\begin{tabular}{lrrrrrr}
\hline \multicolumn{1}{c}{ Titik } & PVI - 1 & PVI - 2 & PVI - 3 & PVI - 4 & PVI - 5 & \multicolumn{1}{c}{ PVI - 6 } \\
\hline A & -4.9612 & 5.0000 & -10.4819 & 5.8051 & -1.4178 & 4.9840 \\
Lv & 20 & 10 & 20 & 30 & 20 & 30 \\
Ev & -0.1240 & 0.0625 & -0.2620 & 0.2177 & -0.0354 & 0.1869 \\
Sta PVC & 49.7 & 80.4 & 99.3 & 110.9 & 145.6 & 193.4 \\
Elev & 156.39 & 155.36 & 155.11 & 154.9504 & 152.4132 & 149.5632 \\
PVC & 59.7 & 85.4 & 109.3 & 125.9 & 155.6 & 208.4 \\
Sta PVI & & & 155.848 & 153.5777 & 151.8946 & 148.8069 \\
Elev & 156.266 & 155.1725 & 154.848 \\
PVI & 69.7 & 90.4 & 119.3 & 140.9 & 165.6 & 223.4 \\
Sta PVT & & 155.11 & 154.0618 & 152.6404 & 151.305 & 148.4244 \\
Elev & 155.8939 & & & & & \\
PVT & & & & & & \\
\hline
\end{tabular}

Tabel 12

Hasil Perhitungan Program Titik PVI - 7 sampai dengan PVI - 12

\begin{tabular}{|c|c|c|c|c|c|c|}
\hline Titik & PVI - 7 & PVI - 8 & PVI - 9 & PVI - 10 & PVI - 11 & PVI - 12 \\
\hline $\mathbf{A}$ & -2.4905 & 4.1413 & 2.3802 & 4.2033 & -7.5174 & 5.2151 \\
\hline Lv & 40 & 40 & 40 & 25 & 30 & 25 \\
\hline Ev & -0.1245 & 0.2071 & 0.1190 & 0.1314 & -0.2819 & 0.1630 \\
\hline Sta PVC & 392.5 & 433.2 & 529.5 & 592.4 & 631.4 & 737.2 \\
\hline $\begin{array}{l}\text { Elev } \\
\text { PVC }\end{array}$ & 146.2205 & 145.1751 & 144.7529 & 146.048 & 148.262 & 148.8981 \\
\hline Sta PVI & 412.5 & 453.2 & 549.5 & 604.9 & 646.4 & 749.7 \\
\hline $\begin{array}{l}\text { Elev } \\
\text { PVI }\end{array}$ & 145.8355 & 144.6371 & 144.959 & 146.5314 & 149.0381 & 149.003 \\
\hline Sta PVT & 432.5 & 473.2 & 569.5 & 617.4 & 661.4 & 762.2 \\
\hline $\begin{array}{l}\text { Elev } \\
\text { PVT }\end{array}$ & 145.2014 & 144.5132 & 145.4032 & 147.2774 & 149.2504 & 149.4338 \\
\hline
\end{tabular}


Tabel 13

Hasil Perhitungan Program Titik PVI - 13 sampai dengan PVI - 16

\begin{tabular}{lrrrr}
\hline \multicolumn{1}{c}{ Titik } & PVI - 13 & PVI - 14 & PVI - 15 & PVI - 16 \\
\hline A & -3.5395 & -9.8958 & 4.6880 & 7.7461 \\
Lv & 25 & 25 & 20 & 30 \\
Ev & -0.1106 & -0.3092 & 0.1172 & 0.2905 \\
Sta PVC & 817.2 & 855.2 & 940 & 994.9 \\
Elev PVC & 152.0463 & 152.9453 & 146.7735 & 144.09 \\
Sta PVI & 829.7 & 867.7 & 950 & 1009.9 \\
Elev PVI & 152.5294 & 152.7808 & 146.0172 & 143.7805 \\
Sta PVT & 842.2 & 880.2 & 960 & 1024.9 \\
Elev PVT & 152.7913 & 151.9978 & 145.4953 & 144.0519 \\
\hline
\end{tabular}

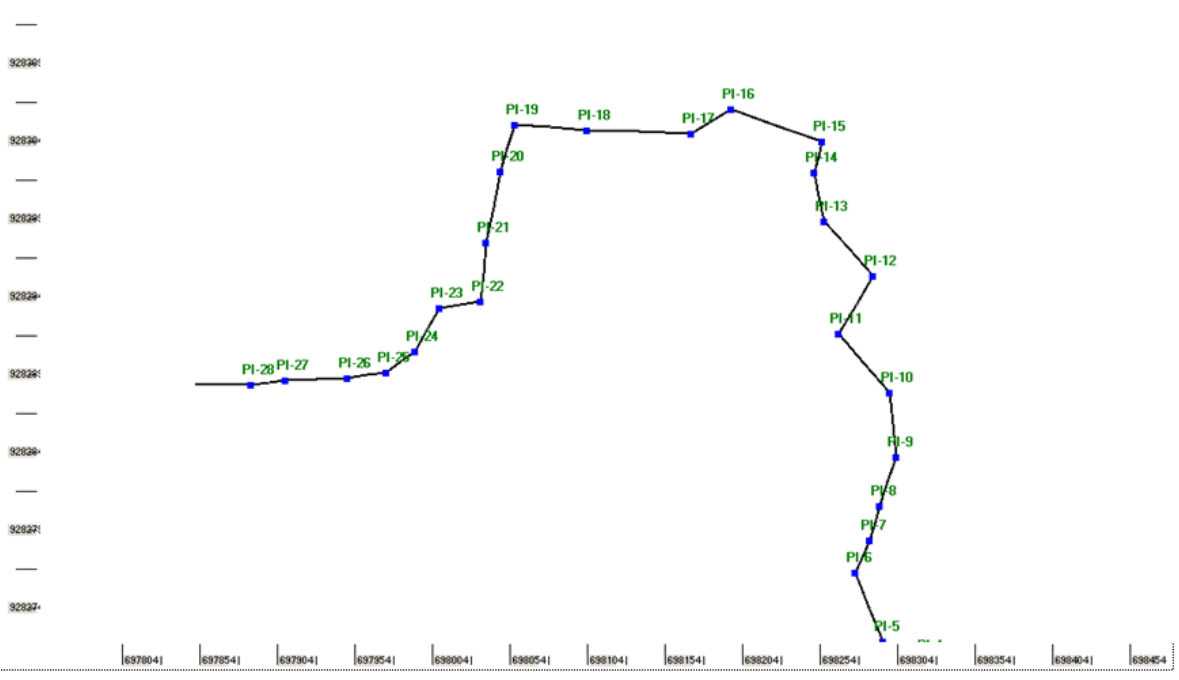

Gambar 5. Trase proyek menggunakan program.

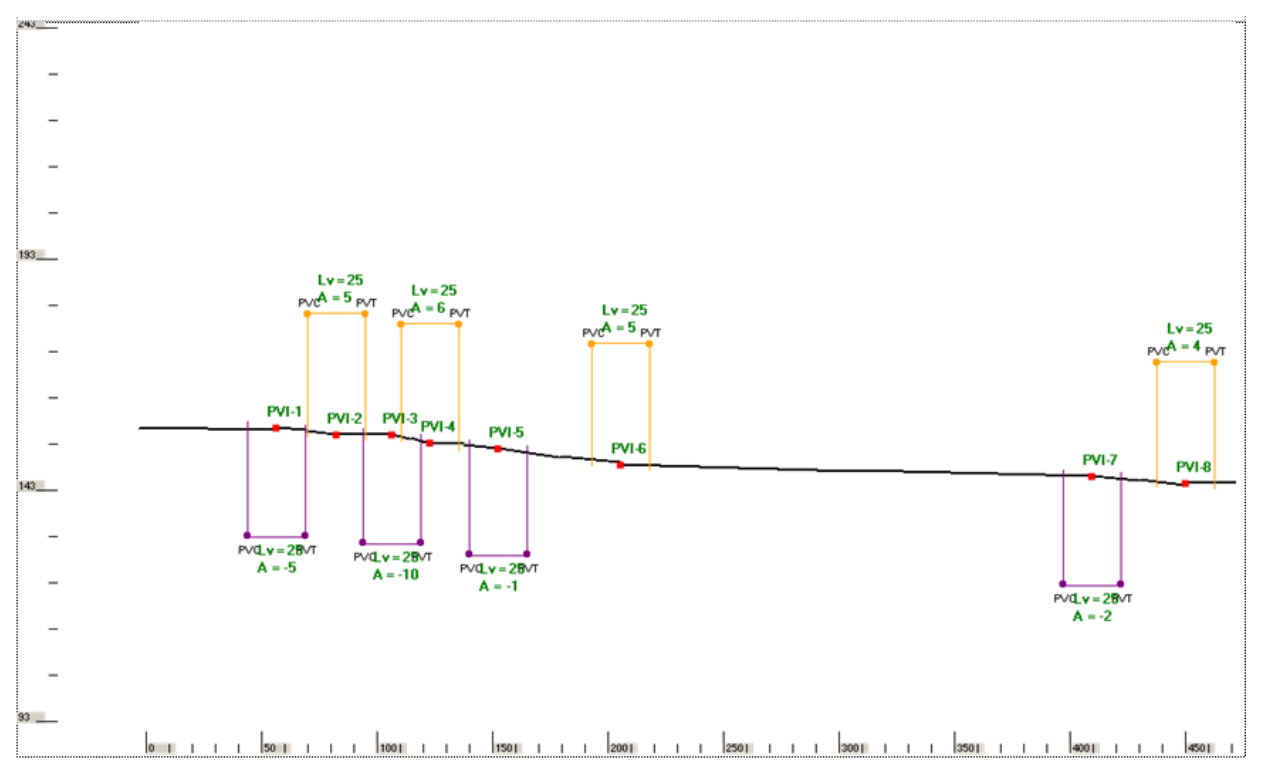

Gambar 6. Alinyemen vertikal proyek menggunakan program. 


\section{PENUTUP}

Pembuatan program perhitungan alinyemen horisontal dan vertikal dengan menggunakan bahasa basic telah berhasil dilakukan. Program ini juga telah divalidasi dengan membandingkan hasil yang diperoleh dengan perhitungan manual dengan selisih sama atau kurang dari $1 \times 10^{-4}$.

Program ini juga dapat menghitung secara cepat multi tikungan dan multi lengkungan dengan demikian dapat dilakukan pada trase yang memiliki kedua hal tersebut. Untuk itu, program ini telah diujicobakan pada proyek perencanaan jalan kabupaten di Kabupaten Bogor dan mendapatkan hasil yang baik sesuai dengan persyaratan dan peraturan perencanaan geometrik yang dikeluarkan oleh Bina Marga.

Penambahan fasilitas penggambaran alinyemen vertikal dan horizontal juga telah dilakukan dengan memanfaatkan data koordinat trase. Kelemahannya adalah, program ini belum dilengkapi dengan fasilitas menggambar tikungan secara detail. Penggambaran tikungan secara detail diharapkan dapat dilakukan pada penelitian selanjutnya.

\section{DAFTAR PUSTAKA}

Departemen Pekerjaan Umum Direktorat Jendral Bina Marga. (1997). Tata cara Perencanaan Geometrik Jalan antar kota. Jakarta: Departemen Pekerjaan Umum. 